\title{
上顎原体照射における線巣型の標準化
}

\author{
愛知がんセンター放射線第 2 部、放射線技術科 \\ (部長 森田皓三) \\ 青山賢一・植田俊男・内山幸男 \\ （論文受理 昭和52年 5 月 9 日） \\ (Code No. 41110, 41312, 41224)
}

\section{STANDARIZATION OF THE TARGET VOLUME FOR THE CONFORMA- TION RADIOTHERAPY OF CANCER OF THE MAXILLARY SINUS}

(Article received: May; 9, 1977)

\author{
by KENICHI AOYAMA, \\ TOSHIO UEDA and \\ YUKIO UCHIYAMÀ \\ Dept. of Radiation Therapy Aichi Cancer \\ Center, Nagoya
}

\section{summary}

Conformation mechanism is capable of fitting the high dose region to the shape and size of any tumor.

In case of the conformation radiotherapy for cancer of the maxillary sinus, the shapes of the target volume and the transverse section of the patient's face are considerably constant in every patients.

The axial transverse tomograms of the maxillary sinus in 52 cases with cancer of the maxillary sinus were traced and the shape of the target volume was decided on each case.

From these procedures it was found out, that the shape of the transverse section of the patient's face can be substituted by the long oval of Haynes's with the maximal difference of $3 \mathrm{~mm}$ (about $3 \%$ difference of the TPR).

Three kinds of cam (small, middle and large size) were prepared on the practical application of this method, because the figure of the transverse section of the patient could be also classified three kinds of long oval of Haynes.

The TPR and the dose can be easily calculated from these standardized figures.

\section{1. 緒—言}

原体照射法は，病巣の形に近い立体的な高線量域肎得 ようとする方法である。従って，原体絞りを制御するた めのカムの形は，病䢟部を含む回転横断写真を基に決め
られる13). 病栄の形は症例毎に異なるが，部位によって は，照射範团及びその形にそれ程大きな変化を認めない ものもある.たとえば，子宮全骨盤㓐の原体照射におい ては，10種類の線巣型に標準化されており6)，体型や病 巣の進展度に応じて対応するカムの組合せを使用する方 
法がとられている.

本論文では，上䫈原体照射に関する《線栄の型》の標 準化を試みた，以下にその結果についてのべる。

\section{2. 目 的}

上顎癌の原体照射に㧍ける線巣型を，頭部横断面の大 きさに応じて標準化し，更に能率的な線量計算法につい てあ検討を加えた。

\section{3. 方法および結果}

\section{1 頭部横断図形の近似}

1971年から1975年までの過去 5 年間に，上䕱癌原体照 射法で治療を行なった患者52例の治療計画記録から，頭 幅，頭長，及び回転中心から皮膚表面までの距離を夫々 測定した. Fig. 1 亿示す様に，回転中心は何れ亦健側眼 球のレンズの位置を基準として, 内側に $5.2 \mathrm{~cm}$, 後方に $4.5 \mathrm{~cm}$ の点である.

上記52例の頭部横断面に対し，回転中心より皮膚表面 までの長さを同じ線束中心軸の入射角度について測定し， 角度每の平均の長さを求めた：次に各々の横断面につい て，頭長，頭幅の長さから，それに相当する Haynes の

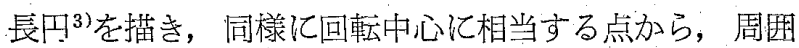
までの長さを平均した. Fig. 2 はとの結果を整理したも のを示す。

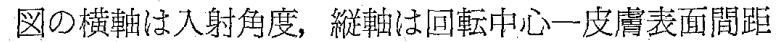
離老表わす，実線注治療計画図の計測值の平均，点線は Haynes の長円の平均宗方.

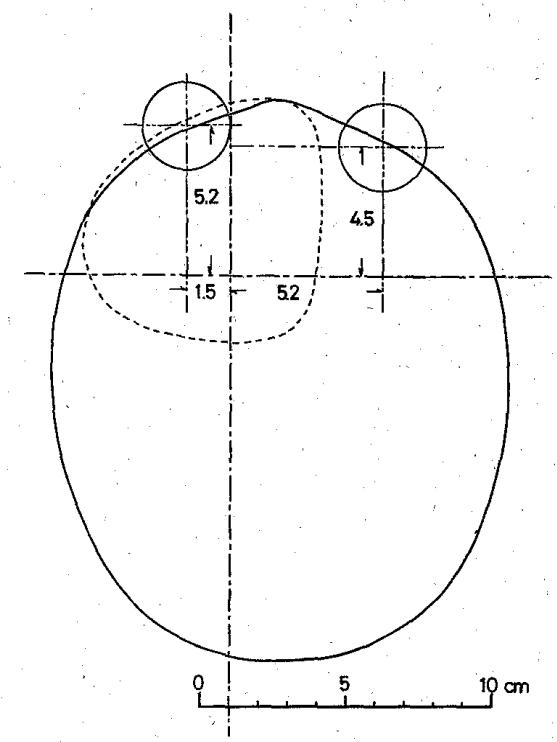

Fig. 1. Expected target area (chain line) and protection area (circle) in conformation therapy for the maxillary sinuses.



Fig. 2. Distance from skin surface to rotation center at the every incidence angle. Solid line was obtained from actual patient contour. Broken line was approximated contour of Haynes's oval.

図において，回転中心加ら各々の入射角度每の治㙩計 画図の計測值の長さと，Haynes の長四にお的る長さと の值を比較すると， 45 度之 105 度近辺で，闭者の差が最 あ大きくなる。そそてで52例の患者について，乙れらの角 度における実測と Haynes の長円との平均值，及び分散 の比の検定を行なった，入射角45度に和りる訢画図の军 測の平均值は6.98, 分散は0.468, Haynes の長円の同 角度に怙ける平均值は7.36，分散は0.608であった。 ま た 105 度では，平均值 $=5.22$ ，分散 $=0.464$ と平均值 $=$ 5.54，分散 $=0.669$ となった。 そこで 45 度及び105度にお りる夫々の平均値を $\mathrm{t}$ 分布表により有意水準 $1 \%$ で検 定を行なう之，次の式に各々を代入する。

45度では，

$$
\begin{aligned}
t=\frac{\bar{x}-\bar{y}}{\sqrt{n_{1} s_{1}^{2}+n_{2} s_{2}^{2}}} \cdot \sqrt{\frac{\left(n_{1}+n_{2}-2\right) n_{1} \cdot n_{2}}{n_{1}+n_{2}}} \\
\bar{x}=\text { 実測の平均值 } \\
\bar{y}=\text { Haynes の長円の平均值 } \\
s_{1}{ }^{2}=\text { 案測の分散 } \\
s_{2}{ }^{2}=\text { Haynes の長円の分散 } \\
n_{1}=n_{2}=\text { 症例数 }
\end{aligned}
$$

$$
\begin{aligned}
& n_{1}=52, \quad \bar{x}=6.98, \quad s_{1}{ }^{2}=0.468 \\
& n_{2}=52, \quad \bar{y}=7.36, \quad s_{2}{ }^{2}=0.608 \\
& t=-2.615 \text { となる. }
\end{aligned}
$$

105度で注,

$$
\begin{aligned}
& n_{1}=52, \quad \bar{x}=5.22, \quad s_{1}{ }^{2}=0.464 \\
& n_{2}=52, \quad \hat{y}=5.54, \quad s_{2}{ }^{2}=0.669 .
\end{aligned}
$$$$
t=-2.147 \text { となる。 }
$$

一方, 自由度 $=n_{1}+n_{2}-2=102$, であるから, 自由度 $1020 \mathrm{t}$ 分布趇から，有意水準 $=0.01$ 亿対する $t_{0}$ は 2.617 
となり有意差は認められないといえる。

次に分散の比を $F$ 分布表により㤫意水準 $1 \%$ での検定 を行なうと，次の式に各々を代入する。

$$
\begin{gathered}
F=\left(\frac{n_{1} s_{1}{ }^{2}}{n-1}\right) /\left(\frac{n_{2} s_{2}{ }^{2}}{n-1}\right) \\
s_{1}{ }^{2}=\text { 実測の分散 } \\
s_{2}{ }^{2}=\text { Haynes の長円の分散 } \\
n=n_{1}=n_{2}=\text { 症例数 }
\end{gathered}
$$

45度では，

$$
\begin{aligned}
& n_{1}=52, \quad s_{1}^{2}=0.468, \quad n=52 \\
& n_{2}=52, \quad s_{2}^{2}=0.608, \quad n=52
\end{aligned}
$$$$
F=0.7698 \text { となる。 }
$$

105度では，

$$
\begin{aligned}
& n_{1}=52, \quad s_{1}{ }^{2}=0.464, \quad n=52 \\
& n_{2}=52, \quad s_{2}{ }^{2}=0.669, n=52 \\
& F=0.6935 \text { となる. }
\end{aligned}
$$

そこで $F$ 分布表より，有意水準 0.01 亿対して， $f_{1}=$ 1.95 と $1 / f=0.5128$ の閭にFの值があるので両者の間に 有意差が認められなりと言える，以上の検定の結果，実 際の横断面を Haynes の長円で表わすととが出来ると考 える.

Fig. 3 は横断面の実測值の平均值を実線で, Haynes の長円の平均值を点線で表わし，両者を横断面上で重ね 合せた図である. Fig. 3 から，実測と Haynes の長円の

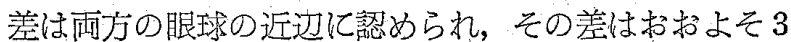
$\mathrm{mm}$ である。



Fig. 3. Averaged contour of actual holizontal cross section of the 52 cases (solid line) and approximated contour with Haynes's oval (broken line).

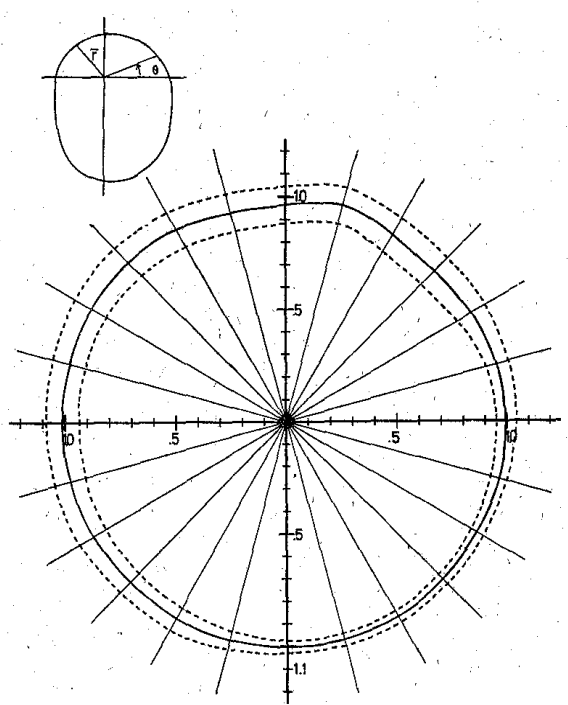

Fig. 4. The ratios of surface to center distance between the actual contour to Haynes's oval shown in Fig. 3.

次に各々の相対する資料52例について，治療計画図に 対する Haynes の長円の比を各入射角度每に計算し，乙 れらの比の平均值之標準偏差を求奴た。れを Fig.4に 示す。図中の害線は平均值を表わし，点線は標準偏差を 示す.

図から両者の比の平均值は，両側の眼球部分の近辺を



\subsection{TPR の值の検討}

以上の結果加ら顔の横断面を Haynes の長田で近似し てすをれ程大きな差のない事が判ったので，次に TPR の值について検討した.

Haynes の長円で近似して求めた TPR と，愳者の横 断面加求めた TPR の比を52例について計算し，その 值が度数分布の正規分布に対して適合しているから゙うか を，K，Peasonの適合度検定法を用いて調べた。

まず度数分布の階級を 9 ，すなわち，自由度 9 で行な った。比の平均值は，0.9977となり，その標準偏差は， 0.0083टなった，そしててれらをそれぞれ母平均，母禋 準偏差とし，正規寻集団分布

$$
\begin{gathered}
f(x)=\frac{1}{\sqrt{2 \pi}} \times \delta \cdot e^{-\frac{1}{2}\left(\frac{x-m}{\delta}\right)^{2}} \\
m=\text { 母平均 } \\
\delta=\text { 母標潐偏差 }
\end{gathered}
$$

を作り， $m=0.9977 ， \delta=0.0083$ を代入し，乙れが度数 分布の資料とよく適合しているから゙うかを有意水準 $5 \%$ $(\varepsilon=0.05)$ で検定した。結果は， $x_{0}^{2}=15.51 （ \varepsilon=0.05$, 自由度 8）に対して, 計算值は, $x^{2}=13.37$ となり, $x_{0}{ }^{2}$ 


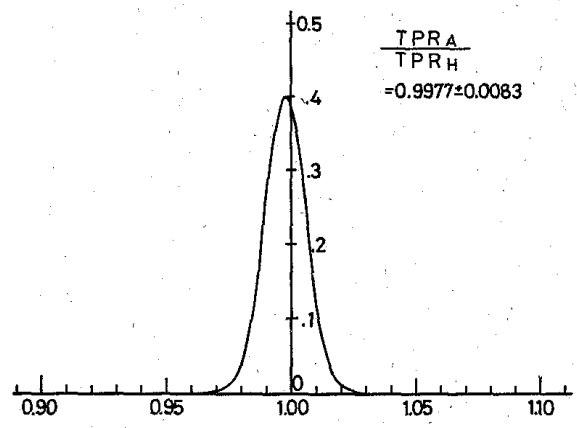

Fig. 5. Distribution of the ratio (TPR (A)/TPR (B)). $T P R(A)=T P R$ of actual transverse section of the patient. TPR $(B)=T P R$ of Haynes's oval.

$>x^{2}$ で適合しているといえるとのととからも治療計 画の横断面を Haynes の長円で表わしても支障がないと 言えそうである。

Fig. 5 は，上記 TPR の計算値の比を正規分布曲線に よって表わしたものである。図より，Haynes の長円で の近似であ，線量の差は最大 $3 \%$ ある.

以上の結果汃ら，治㙩計画の横断面を Haynes の長円 で表わしても，横断面上では，眼球部分で $3 \mathrm{~mm}$ 活での 違いがあるのみで，その他の部分は，ほとんど一致する。 また，TPR の計算で法，最大でも $3 \%$ 違いであると とがわかった。

\section{3 頭部断面の大きさによる分類}

52例の息者の横断面につひて，頭長之頭幅の平均値を 求めると, 頭長の平均は $19.75 \mathrm{~cm}$, 頭幅の平均は15.56 $\mathrm{cm}$ となった：そてで頭の大きさに応じて，上記52例を L; M; S の 3つのタイプに分類した.

52 例の頭部横断図より測定した頭長の最大値は，21.5 $\mathrm{cm}$, 頭幅は $17.0 \mathrm{~cm}$, 頭長の最小值は $18.1 \mathrm{~cm}$, 頭幅は $14.1 \mathrm{~cm}$ であった. そこで頭長の平均值 $=\bar{D}_{L}$, 頭幅の平 均值 $=\bar{D}_{W}$, 代対し, $\pm 0.5 \mathrm{~cm}$ の範囲に入るあのを $\mathrm{M}$, $\mathrm{M}$ 以上の值の範囲安 L, M 以下の值の範囲のあのを $\mathrm{S}$ と てのように分類し，L及びS についての平均を求めると， した，Lの平均值は，頭長が $20.8 \mathrm{~cm}$ ，頭幅茂 $16.5 \mathrm{~cm}$ となった. S の平均值は，頭長が $18.5 \mathrm{~cm}$, 磌幅が 14.6 $\mathrm{cm}$ となった. $\mathrm{L} ; \mathrm{M} ; \mathrm{S}$ の人数比は, 18;18;16 となり活 等しい割合に分けられた. このように分類した $\mathrm{L}, \mathrm{M}$, S，の各々の中心方ら皮膚面までの長さの平均值结， Fig. 6 亿示す.

Fig. 6 は, Fig. 2 之同様に L; M ; S の各々の入射角 度每の回転中心加ら皮膚表面までの長さを示すすので， 横軸に入射角度，縦軸に各々の長さを表わす。，図中の点 線は $L$, 実線は $\mathrm{M}$, 一点鎖線は $\mathrm{S}$ を示す。

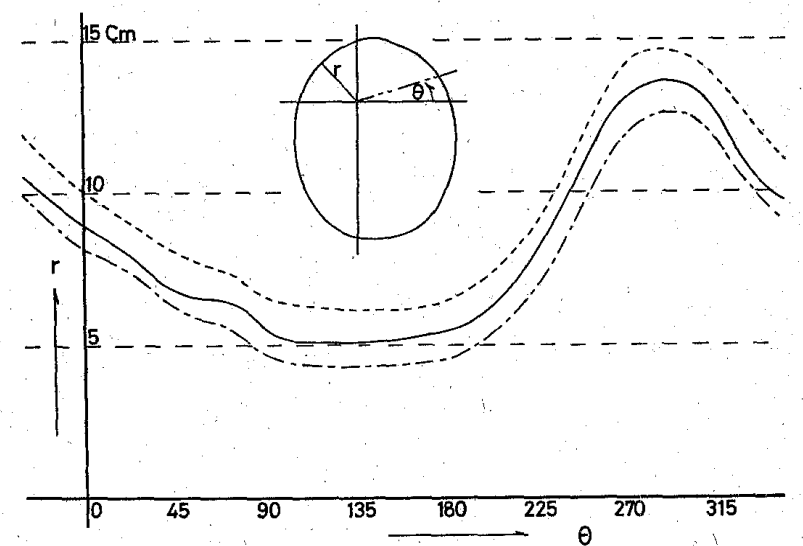

Fig. 6. Relationship between beam rotation angle $(\theta)$ and $r$ (sec Fig.) in 3 sizes of head. A dotted line $=\mathrm{L}$, solid line $=\mathrm{M}$, chain line $=\mathrm{S}$ at each mean value.

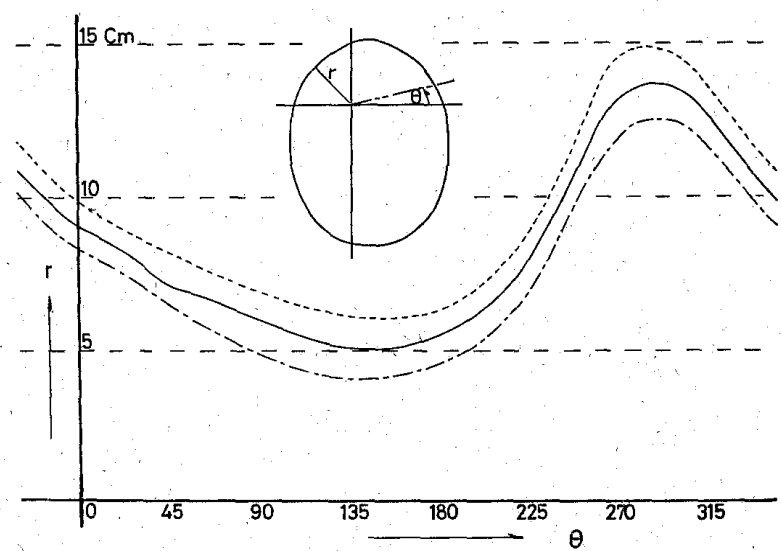

Fig. 7. Relationsphip between rotation angle $(\theta)$ and $r$ (see Fig.) in 3 modified contour (Haynes's oval). A dotted line $=\mathrm{L}$, solid line $=\mathrm{M}$, chain line $=\mathrm{S}$.

図より，頭長上頭幅はほほぼ相関関係にあり，上記の分 類方法の籍团から外れるすのはない。すするわち, 頭長が 極端に大きく，頭幅力極端に小さいむの，出るいはその 逆の状態のものはほとんざないという事ができる。

Fig. 7 亿，Haynes の長円で近似した場合でも同様の 結果を得る事を亦す。

\section{4 線巣型の標準化}

頭部横断面の輪㔀を上記 $\mathrm{L} ; \mathrm{M} ; \mathrm{S}$ 亿分類 $\mathrm{C}$ ，夫々の


ちカムの形を整理し, その平均的な形乞寸法を求めた.

この結果学 Fig. 8 と Fig.9 亿示す.

Fig. 8 は眼球定含む横制面（横断面 1) 飞相当するす の, Fig.9 は, それより $3 \mathrm{~cm}, 6 \mathrm{~cm}$ 足方の横断面（横 断面 $2 ， 3 ）$ 亿相当する線巣形を整理した平均的な力ムの 形を示す。 




Fig. 8. Rotation center to circumference distances of conformation cam No. 1 in 3 sizes of head. A dotted line $=\mathrm{L}$, solid line $=\mathrm{M}$, chain line $=\mathrm{S}$.

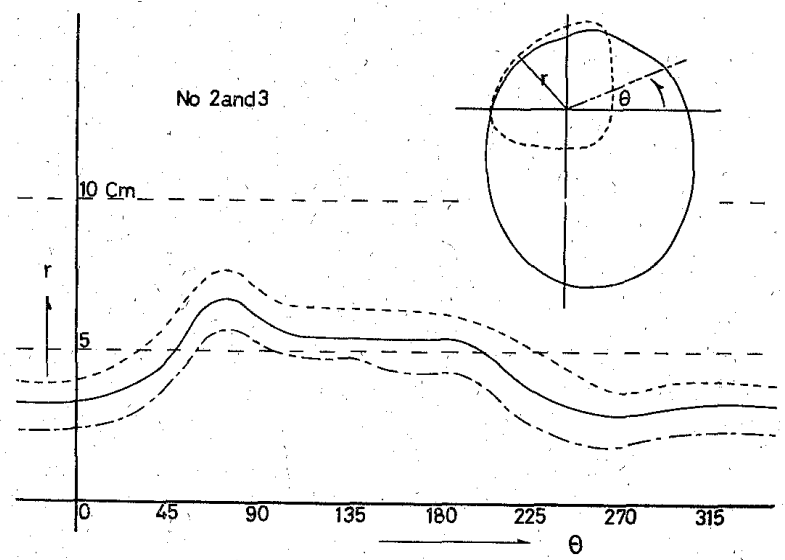

Fig. 9. Rotation center to circumference distances of conformation cam No. 2 and 3 in 3 sizes of head. A dotted line $=\mathrm{L}$, solid line $=M$, chain line $=\mathrm{S}$.
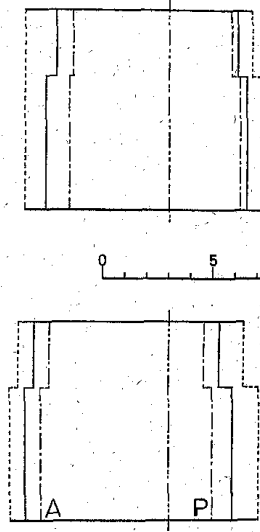

Fig. 10. A-P and lateral view of the field produced with conformation cams shown in Fig. 7 and 8 for 3 sizes of head.

A dotted line $=\mathrm{L}$, solid line $=\mathrm{M}$, chain line $=\mathrm{S}$.
図中の横軸は入射角度，縦軸は回転中心からカムの周 辺までの長さを示す。図の実線は，頭部横率面の大きさ がMの範囲で使用された平均の長さ，同様に点線が L, 一点鎖線が $\mathrm{S} ，$ 亿相当するカ厶八の寸法を示す。

Fig.8，9 亿示した頭部の寸法 L；M；：亿相当する力 ムによって作られる照射野は，Fig. 10 亿示す.

図中の上瓦は正面の照射野を，下図は側面の照射野を 示方。頭部の寸法が，L，M，S，相当する照射野を夫ね， 点線, 実線，一点鎖線で示した．又二点鑽線は回転中心 軸を示与。

以上，眼球を含む嗔部横断面の大きさに対する区分と， それに対応した原体照射用カムによって形成される照射 野を数值的に示したのが，Table 1 である.

Fig. 11 は，頭部横断面に対するカ厶の形と，正面， 側面の照射野为いかなる関係に㐫るかを，Mの大きさの 頭部について示したもので，他の大きさのものについて あほほ同様な傾向である。

Table 1. S/L (=field area/field perimeter) value of 3 conformation fields applicable to the head sizes (S.M.L.) at transverse section through the eye-balls.

\begin{tabular}{l|c|c|c|c|c}
\hline \hline & $\begin{array}{c}\text { Head } \\
\text { length }\end{array}$ & $\begin{array}{c}\text { Head } \\
\text { breadth }\end{array}$ & \multicolumn{3}{|c|}{$\mathrm{S} / \mathrm{L}$} \\
\cline { 3 - 6 } & $(\mathrm{cm})$ & $(\mathrm{cm})$ & $\begin{array}{c}\mathrm{AP} \text { view } \\
(1)\end{array}$ & $\begin{array}{c}\text { Lateral } \\
\text { view (2) }\end{array}$ & $\begin{array}{c}\text { mean } \\
{[(1)+(2)]}\end{array}$ \\
\hline $\mathrm{S}$ & $<19.25$ & $<15.06$ & 2.03 & 2.02 & 2.025 \\
$\mathrm{M}$ & $19.75 \pm 0.5$ & $15.56 \pm 0.5$ & 2.18 & 2.21 & 2.195 \\
$\mathrm{~L}$ & $>20.25$ & $>16.06$ & 2.42 & 2.44 & 2.430 \\
\hline
\end{tabular}

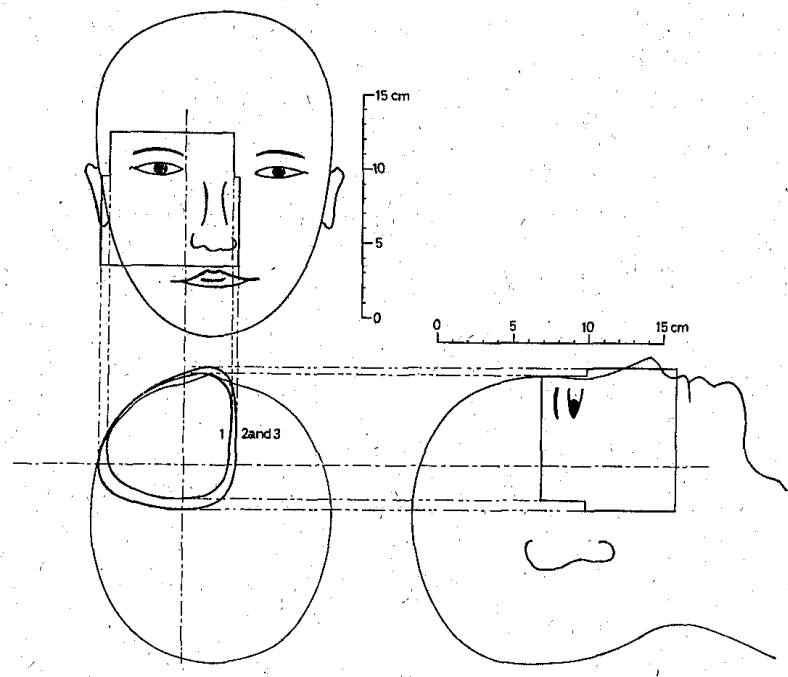

Fig. 11. Relationship between portal (A-P, Lateral), and top view of conformation field for the maxillary sinusses. 


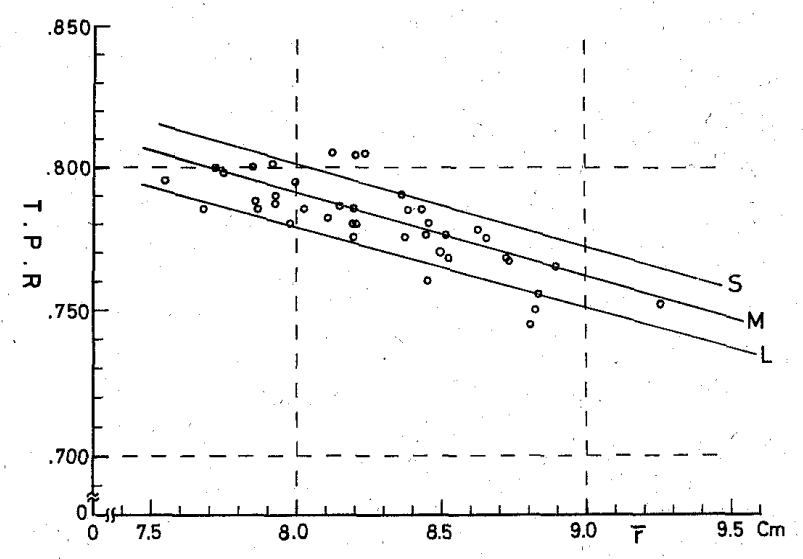

Fig. 12. TPR curve against 3 types of conformation target volume indicated in Table 1.

\section{5 標準線量に対する TPR 図表}

Table 1 亿示す樣に，上顎癌に対して行なう原体照 射の線巣の型を 3 種類, すなわち頭部の寸法に応じて L,


に示した各線巣型の照射野の $\mathrm{S} / \mathrm{L}$ の值から, 夫々の線 巣型に刘応する TPR 曲線を描いた。

Fig. 12 は， $6 \mathrm{MeV} \mathrm{X}$ 線它使用した場合の TPR，曲線

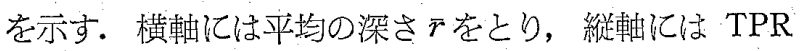
をとり， 3 種類の照射野の正面, 側面の $\mathrm{S} / \mathrm{L} の$ 平均值 をパラメータにとってある.

図中の○印のプロットは，治潦計画記録にある TPR の値を示したもので，何れも殆んどこの曲線内に入って いる. 各点が曲線上に一致しないのは，カムの形，すな わち照射野の大きさが標準化したものと多少異なるから であると考える. この曲線を用いれれ゙，頭の大きさに応 じ，標準化した 3 種類の線紧型の一つを選択すれば，平 均の深さ（てれは頭の大きさをHaynes の長円で近似出 来る.) 加ら容易に TPR を求めることができる.

\section{4. 考 按}

上額癌に対して原体打抜き照射を行なう場合，回転横 断写真上にカムの形が医師によって描かれる. しかしそ れは上記のように頭の大きさを， L, M, S に分類するこ とにより，力ムもそれに店じ大きさを沠定する事が出来 る. しかし, 病坚の進展度, 又頭の大きさが Table 1 K 示す值より極端に異なっている場合, 又それ以外の何ら 汃の理由で病巣の大きさ（カムの大きさ）を変化させな くてはならない場合には，個々に応じたカムを作る必要 がある. しかしそのような特殊な例は，今回私共力゙処理 した52例中には含まれないのでばとんどのものが適忘出 来ると考えられる. 頭の大きさは, Haynes の長円で近
似するととが出来るので，そのパターンに合ったカムを 使用すれば，線量計算，及び力ムの作成を簡略化する事 が出来る.

\section{5. 結 論}

上顎癌原体照射治療を行なう場合，上擷部の病栄はほ ぼ箱形の骨飞国まれているため, 照射範围す比較的限定 されて居り，患者每の差もそれ程大きくない。

頭の大きさは, 治療計画図の頭部横断面を整理した結 果, $\mathrm{L} ; \mathrm{M} ; \mathrm{S} の 3$ 種類に整理するととが出来, 又平均 の深さを計算する時には，それをHaynes の長四で近似 する事が出来る。近似した場合，実際の横断面との差は， 両側の眼球部分で約 $3 \mathrm{~mm}$ 程度の差のみで, TPR の比 においては，最大であ $3 \%$ 以下であった。

線巣の型（カムの大きさ）については，上記の頭の大 きさ， L; M; S についてあそれぞれ平均值を求めた結 果，それぞれのカム (照射野) の型が決った。 その分類 された頭部横断面の平均の $\bar{r}$ と照射野の大きさによって TPRのグラフを作り，簡単に TPR を求める事が出来る。

\section{文献}

1）青山賢一他：上顎癌原体照射時の眼球保護に使用さ れる打拔咬収体の材質の検討，日放技学誌，30， 348-352, (1974).

2) Busch, M.: Approximation and variation of human body surface for three dimensional dose calculation in teletherapy, Role of computers in radiothrapy. 77-91, IAEA, Vienna, (1968).

3) Haynes, R. H. and Froese, G. : Idealized body contours in Radiation dosimetry. Acta Radiol. 48, 209-226, (1957).

4）木村干明，植田俊男： $6 \mathrm{MeV} \mathrm{X}$ 線による上顎癌原 体照射の基礎実験，日放技学誌，30，343--347，(19 74).

5) 木村于明他：原体照射機構による二軸振子照射の線 量分布と線量評価，日放技学誌，32，463-468， (1977).

6) 森田皓三，筧 正兄：子宮頸顎癌に対する全骨盤㬴 内原体照射の際，患者の体型と照射線栄との関係， 日医放誌，35，780-787，(1975).

7）森田皓三：子宮颁癌飞対する原体照射法の発展，臨 床放, 19，417-418，(1974).

8）森田皓三：上顎煰に対する原体照射法による放射線 治療乙眼障害，癌の臨床，21，560-564，(1975). 
9）国呮清典：統計学初歩（数学セミナー増刷)，宝文 館, (1974).

10）植田俊男，木村千明：回転照射におりる線量訐算の 簡便法，日放技学誌，28，55-58，(1972).

11）植田俊男，木村干明：等時間曲線认よる原体照射機 構の検討，日医放誌，34，889-897，(1974).
12）植田俊男，北畐 隆：眼球を保護する脑下垂体のリ ニアアクセラレータによる運動照射法，日医放誌， 28, 1002-1009, (1968).

13）植田俊男：原体照射法の技術と応用，日放技学誌， $32,217-248$, (1976). 